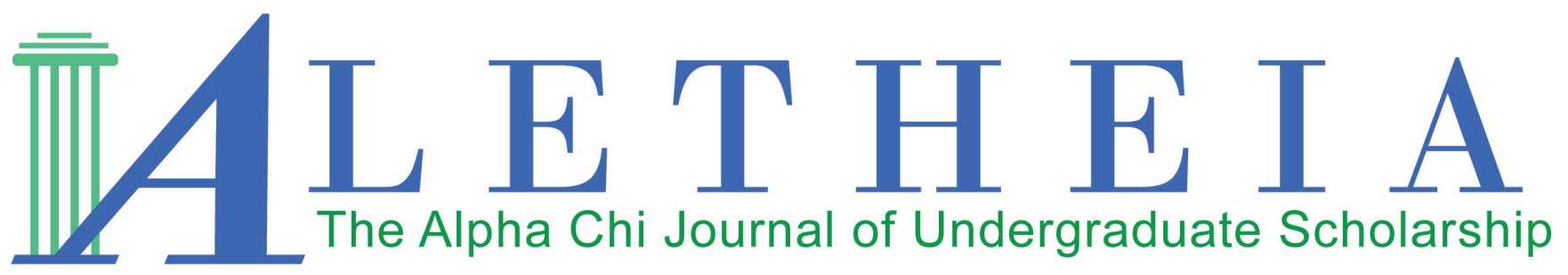

Volume 3 | Issue 1 | 2018

\title{
Promoting Literacy on Isla Muieres: An Ethnographic Perspective
}

\author{
Jessica Petty \\ East Central University \\ Oklahoma Gamma Chapter
}

Vol. 3(1), 2018

Article Title: Promoting Literacy on Isla Muieres: An Ethnographic Perspective

DOI: $10.21081 / \mathrm{AX} 0166$

ISSN: $2381-800 \mathrm{X}$

Key Words: Mexico, Literacy, Promoting Literacy, Mexican Education, Isla Mujeres

This work is licensed under a Creative Commons Attribution 4.0 International License. Author contact information is available from the Editor at editor@alphachihonor.org.

\section{Aletheia-The Alpha Chi Journal of Undergraduate Scholarship}

- This publication is an online, peer-reviewed, interdisciplinary undergraduate journal, whose mission is to promote high quality research and scholarship among undergraduates by showcasing exemplary work.

- Submissions can be in any basic or applied field of study, including the physical and life sciences, the social sciences, the humanities, education, engineering, and the arts.

- Publication in Aletheia will recognize students who excel academically and foster mentor/mentee relationships between faculty and students.

- In keeping with the strong tradition of student involvement in all levels of Alpha Chi, the journal will also provide a forum for students to become actively involved in the writing, peer review, and publication process.

- More information and instructions for authors is available under the publications tab at www.AlphaChiHonor.org. Questions to the editor may be directed to editor@alphachihonor.org.

\footnotetext{
Alpha Chi is a national college honor society that admits students from all academic disciplines, with membership limited to the top 10 percent of an institution's juniors, seniors, and graduate students. Invitation to membership comes only through an institutional chapter. A college seeking a chapter must grant baccalaureate degrees and be regionally accredited. Some 300 chapters, located in almost every state, induct approximately 11,000 members annually. Alpha Chi members have been "making scholarship effective for good" since 1922.
} 


\title{
Promoting Literacy on Isla Mujeres: An Ethnographic Perspective
}

\author{
Jessica Petty \\ East Central University \\ Oklahoma Gamma Chapter
}

\begin{abstract}
This ethnography, using a double case study to examine and diagnose reading difficulties in a multiple language-speaking, private elementary school, took place on Isla Mujeres in the state of Quintana Roo, Mexico. It explored local cultural aspects of education and literacy to analyze how multilingual students learn to read. Through diagnosing strengths and weaknesses, methods for youth literacy improvements can be implemented both on Isla Mujeres and with U.S. educators.
\end{abstract}

Key words: Mexico, Literacy, Promoting Literacy, Mexican Education, Isla Mujeres

\section{Introduction}

I went to Isla Mujeres to study anthropology with the goal to make myself a more culturally sensitive teacher in Oklahoma, as well as to learn about the different ways education works and the different ways students learn in an Isleño-Spanish environment. My role during my experience abroad was to observe the connections between attitudes about literacy within the culture as a whole, and what concepts of society play into those attitudes. I applied what I learned to create not only an individualized assessment and plan for each student tested but also to create a plan for enhancing the literacy attitudes of the island community into an environment that embraces and encourages literacy.

\section{Methods}

I utilized anthropological and educational methodologies in conducting my research and implementing proposed program suggestions. I began by conducting case studies of two students who attended a school on Isla
Mujeres. "The case study has been of increased value to students of research in education, psychology, sociology, and anthropology ... This methodology bridges the gap between the stereotyped, factual community survey, and the personality-culture community study" (Symonds \& Ellis, 1945). I used the Ekwall/Shanker Reading Inventory for my case study guidelines (Shanker \& Cockrum, 2014). While conducting these two case studies, I also conducted an ethnographic research technique known as participant observation, in which one examines details of the environment, behaviors of people, and subtleties of interrelationships both from an insider and outsider perspective to seek meaning that often lies below the surface and can easily be missed (LeCompte \& Schensul, 1999, 85-86). This method enhanced my understanding of the students' learning environment. One author discussed the importance of constructing data out of experience (Wolcott, 1994, 3). This discussion helped me to understand the students' literacy practices in a broader and culturally aware context and has therefore allowed me to interpret the culture of literacy learning. In addition to this, I conducted semi-formal and infor- 
mal interviews with parents and teachers involved in the case studies to discuss the methods of teaching and learning to read that they or their children used. These ethnographic methods, educational methods, along with participant observation, gave me a deeper understanding of the context of literacy learning on the island, specifically among the students attending a small school on Isla Mujeres.

In addition, I conducted a survey to ascertain more specific information on the perceived value of literacy on Isla Mujeres and asked for ideas on ways to improve the perceived value of literacy. In the survey, I asked 10 questions. First, I asked for the ethnicity and residential status of the project participants on the island for the purpose of this study. I did not include data from nonMexican, non- residential individuals. My questionnaire considered the following 10 topics:

- how residents on Isla Mujeres perceive and value literacy

- how often they read to their children

- what types of materials they read to them

- a numerical rating about how much residents on the Island value literacy

- how often their children read to them

- whether they feel that it is common for other people to read to their children

- what types of materials the residents on the island read

- how often they read for pleasure

- what motivates residents to read the most

- ideas for how the community can encourage more people to read at home

From this survey, combined with ethnographic interviews and participant observation, I hoped to gain an understanding of the culture behind the perceived value of literacy based on the written and verbal answers of the residents and observations on the island.

\section{A Verbal Snapshot of the Private School}

The small school on Isla Mujeres is a private school in an older house, maybe 1,000 sq. $\mathrm{ft}$., with a small garden out front. The front garden is protected by a concrete wall and gate. The garden has student art, plants, murals, sculptures, toys, and a winding sidewalk that leads from one end of the schoolhouse to the other. There are soccer balls and small shovels where children play and practice gardening. The school has an open floor plan with arches and wall cut-outs, and the windows stay open for the warm, fresh, ocean-scented, air to keep the students from getting overheated in the mid-summer temperatures. The light blue walls are covered in colorful art by the students and the floors are an old, chipped tile. There are only nine students and two teachers. Both teachers are bilingual (Spanish and English), one spoke Spanish as their first language and one spoke English as theirs. The students are of different ethnicities, and all are bilingual (English and Spanish), and one is trilingual (English, Spanish, and Hebrew).Their ages range from six to 11 . The teachers provide the lessons together using both Spanish and English. They either take turns teaching in one language or teach using both languages, going back and forth and translating.

The students watch slideshows to learn geography, taught by a well-travelled sailor and mother of one of the students. The slideshows are projected onto a hanging sheet, which is draped over a long string that spans the main classroom. The students read excerpts from scientific magazines and journals about microscopic life and water found on Mars. They read in Spanish, and then a student translates the material to English. The space is small, intimate, and the rooms are filled with a feeling reminiscent of family closeness by the class and the teachers.

When the day is over, the students are picked up one-by-one by their families. One student is picked up by his abuela, a Spanish word meaning grandmother, and all of the other students run to his grandmother and give her hugs and kisses. The school culture is one of community, friendship, encouragement, and a kind informality. The school is unique, borrowing small aspects of Mexican-Isleño and American culture. The children don't wear shoes, and they might stop class to run in awe towards kittens outside. They call their teachers by their first names and respect each other as individuals while treating each other as equals and family, despite the immense diversity among the students and teachers. Their learning environment is collaborative and social.

\section{Case Study Explained}

The case study format used language as a learning tool for students in American schools. It was adapted to check for reading difficulties in Spanish speaking, and in this case, with multilingual students. The purpose of this ethnographic case study was to work one-on-one 
with a Spanish-speaking student or students who were experiencing reading difficulties in English as a second language. Additionally, it served to diagnose where/ what the issues were, where they could be improved, and how such improvements could be made both in the classroom and at home. The case study consisted of seven components and required a minimum of 15 hours with each student. It assessed reading attitudes, reader self-perceptions, concepts of print, phonemic awareness, sight words and phrases, structural analysis, comprehension, and fluency. By studying the reading skills in a Mexican-immersion setting, results were expected to reflect many of the difficulties English language learning (ELL) students face in American education. This case study used applied methods to create a useful assessment tool for the teachers on Isla Mujeres to use in language arts subjects and focused directly on areas of improvement for the individual needs of each student.

\section{Results/ Reading Speed Discussion}

I assessed the English reading skills of two multilingual students attending the small school on Isla $\mathrm{Mu}-$ jeres. One student speaks two languages fluently and the other student speaks three. One student speaks mainly English at home but is fluent in Spanish and speaks both Spanish and English at school. The other speaks mainly Hebrew at home and speaks Spanish and English fluently at school and outside of school. Both students scored on-level on almost all components of the assessment for their age and grade in accordance to second grade American academic standards, with the major exception being reading speed, which is a major component of fluency, and contractions.

The results of their reading speed were of special interest to me because both students' comprehension abilities were above average, scoring close to $100 \%$ each time. However, their speed was far below average, taking sometimes around two to three minutes to read around 75 words orally or silently. I chose to focus more on the reading speed because contractions can be easily taught, while reading speed is something that comes with time and practice. It was also puzzling that their comprehension was so high while having such a low reading speed. "With instantaneous execution, reading fluency is achieved so that performance is speeded, seemingly effortless, autonomous, and achieved without much consciousness or awareness" (Jenkins, 2001, 239-256).
Fluency is the ability to read words quickly, accurately, and with expression, so fluency therefore appeared to be a weakness for the students. However, the students still understood exactly what they were reading. Reading fluency is a reflection of overall reading competence, and that fluency is highly connected to comprehension. Reading competence may be measured by both comprehension and fluency. The latter is a significant factor in decoding words and comprehending what is read. The correlation between fluency and reading comprehension is high. Therefore, reading comprehension is connected to fluency but is also a distinct aspect of reading competence (Jenkins, 2001, 239-256). So, why did the students score so high on comprehension but so low on fluency or reading speed? My hypothesis is that multilingual students take more time to decode and process what they are reading, which makes their reading in English less automatic.

After doing further reading over automaticity and reading speed of multilingual people, I found this statement to support my analysis: "Practice and experience with a language typically lead to faster processing, which is commonly reflected in various ways, including faster lexical decision times, faster rates of speaking and reading, and better ability to process rapid speech" (Segalowitz, 2005, 375). My data confirms research that says multilingual people read slower in their second or third language or less automatically due to processing and translation reasons. This data suggests that multilingual students simply need more practice reading in their second language to help with their speed.

In the process of applying my fieldwork and background research in an effort to strengthen areas of weakness found with the students, I wrote two separate and individualized comprehensive summaries. I did this not only to strengthen my case study findings, but for reciprocity within the community. There were multiple parents who wished to participate in the case study, each wanting a comprehensive study of where their children were struggling and where they were successful regarding literacy and their learning. I was able to complete two studies based on the amount of time allocated to my research. I believed it would be important and helpful to the school and the students to perform more than one case study. These involved the two case studies of which I sent the results to a parent of each student. I tried to minimize the jargon so that the parents, who had no formal training in the methods of teaching reading, could 
understand exactly what was happening. Enclosed in the document were ways to improve their child's literacy at home. I included keywords for them to search online for activities and games to do together as a family, as well as a few other recommendations like reading together at night. I also asked that they pass the diagnostic paperwork to their teacher when summer break was complete, so those areas could really be focused on and improved during the next school year. The summary also included all of their strengths, as well as their areas of improvement. This knowledge is crucial to focus on strengthening specific targeted areas.

\section{Value of the Case Study}

Spanish is the primary language spoken on Isla $\mathrm{Mu}-$ jeres. Spanish is also the primary non-English language spoken in the U.S. (Gonzalez-Barrera \& Hugo Lopez, 2014). The number one language spoken by English Language Learning (ELL) students in American schools is Spanish. This study will be beneficial to teachers in primary/elementary education who have ELL students in their classroom. While the students in this case study are fluent in English verbally, they can be considered ELL in their literacy skills due to being taught Spanish phonetics first. Their reading and writing skills are stronger in Spanish. This case study also shows a glimpse into the reading automaticity and speed of students who speak more than one language. Reading more slowly, or less automatically, can be a disadvantage for students in early primary school. ELL students process more words, and, therefore, need more time to read. Improving their reading speed should be the next step, and it is worth investigating how to do this.

\section{Early Reading Methods for Multilingual Students}

One of the school teachers I worked with helped me gain a better understanding of her language arts teaching methods as portrayed through her statement:

"We have a pretty unique program, so we were able to implement a number of strategies as we worked to find the ones that best suited the kids. We really listened to their interests and focused on their strengths, so it was an ever-changing format. We used flash cards, board games, word play, targeted readers, work books, puzzles, incorporated art, scrabble pieces, other manipulatives and physical activities in our lessons among other methods to spark their interest and stimulate their curiosity.

At first, we did letter recognition in both languages, then focused in on Spanish and understanding syllables and grouping letter sounds. Spanish is straightforward in its phonetic structure so we worked on mastering the concept of how to break down words into groups of letters and sounding out before we really started diving into English phonics.

We tried to keep it balanced, going back and forth between days in English and Spanish, doing reading comprehensions and writing exercises in both languages. Literary fundamentals overlap but the phonetic element is where we had greater division, so as the native English speaker I taught the English phonics and our native Spanish speaking teacher ran the Spanish classes."

After seeing how these students learn early literacy in multiple languages, and how the teachers utilize reading strategies in more than one language while teaching, I realized learning Spanish phonics before English affected the two students' reading speeds. This is due to the time it takes to process the English phonics, which they learned after Spanish phonics. It takes longer to translate and interpret what they are reading. Although their spoken first languages differ from one another, they both struggle in the same areas and are highly skilled in the same areas.

\section{Purpose for the Study}

The purpose of my study was not to assess the quality of education there, but to simply find ways to increase the culture behind literacy, especially reading. I weighed the possible ethical dilemmas behind increasing reading and concluded that no matter how educated a population is people can always read more. A comparative study of over 25 countries concluded that home literacy environments influence children's reading performance (Park, 2008, 489-505). Domain analysis is commonly utilized in qualitative research in order to help narrow categories of information for further, more detailed exploration of specific data. My overall research yielded three key domains: early home literacy activities, parental attitudes toward reading, and number of books at home (Leech \& Onwuegbuzie, 2008, 587-604). 


\section{Survey Results}

After my case study was complete, I shifted my research to literacy on the Island as a whole and the culture surrounding it. Reading fluency happens when reading is practiced more. So, one way to create a more fluent population is to simply read more. To get a population to read more, reading must be culturally valued I asked myself the questions, "How can we get more people to read here? Is literacy valued on Isla Mujeres?' Literacy is a component of being educated and there are mixed opinions on whether education is a priority on Isla Mujeres. Many informal interviews and discussions with locals on the island lead me to understand that many residents disagree with each other about the island's education style and quality. This can be for a multitude of reasons, one being that some of the jobs that support tourism, for example, fishing or dishwashing, do not always require literacy. One informant said that many people on the island do not even know of the existence of the public library or the bookstores.

There is only one small public library on the island, and it is not frequently used. When I visited the library, there was only one employee sitting at a desk, and the checkout sheet was filled out mainly by the teachers I was working with who were checking out books for their students. It is located near the school where I performed my case studies, in an area that is in a rather hidden location with no signs to draw attention to it. Downtown there are a couple of used bookstores that are mostly comprised of books left behind by English-speaking tourists.

I investigated my questions about how to improve literacy using different ethnographic methods such as informal conversation with locals, formal interviewing, and a survey. My survey results varied greatly from respondent to respondent. Isleños, (a Spanish word meaning islander,) on Isla Mujeres perceive literacy as important, and they think others on the island have the same perception. They also think that most people read frequently to their children. One Isleño, when asked if there was a way to encourage reading at home, responded saying that it is possible.

"Si, si se implementa y se habla de la importancia, ya que mejora tú léxico y te ayuda a conocer y dejar la ignorancia a un lada. / Yes, if it is implemented and the importance is spoken, since it improves your lexicon and it helps you to know and leave the ignorance aside."
"Research has been unanimous in reporting that a variety of relationships exist between characteristics of the home environment and children's subsequent reading performance in school" (Aulls \& Sollars, 2003, 164178). The benefits of a positive literacy environment at home reflect positively on a student's literacy performance. This environment is an important key when looking at the overarching culture of literacy on Isla Mujeres and the development of better reading education and more literacy advocacy on the island.

When asked what encourages locals to read, some informants responded that expanding their vocabulary and being a successful person is motivation for them. Knowing this is the first step to incentivizing or inspiring more reading at home. My survey responses support my claim that Isleños see a connection between literacy and success in life.

Another respondent suggested creating more cultural activities that center on reading to improve literacy:

"Se necesitan campañas de lectura y cultura como obras teatrales, música etc, para que niños y adultos comprendan las obras literarias, es muy fácil distraer a personas con otro tipo de actividades y poco frecuentes son las culturales como el de leer al menos un libro y se requiere que los libros estén a disposición de los niños como bibliotecas, tiendas de libros etc. Pocas personas siendo estudiantes o no sabes que hay biblioteca en isla mujeres. / Reading and culture campaigns are needed, such as plays, music, etc. for children and adults to understand how literacy works. It is very easy to distract people with other types of activities, and cultural activities such as reading at least one book. Books are required to be available to children such as libraries, bookstores, etc. Few people being students or do not know that there are libraries on Isla Mujeres."

\section{Conclusions and Implications}

Given that my survey, completed by 22 locals, and formal and informal interviews strongly support people's nearly unanimous desire to increase literacy and improve reading skills, it seems important to continue to find ways to support the community's desire for this to happen. My survey also asserts that fiction and social media are the top two forms of reading that people enjoy doing, along with nonfiction and magazines. This information could be useful in propelling some future work in literacy on this island forward, especially when 
thinking of ways to encourage more reading at home. Some other responses to encouraging literacy included providing free books to people, book donation campaigns, weekly library programs for children of all ages that includes cultural activities, story times, science experiments, dramatic plays, and music classes. Monthly reading assignments for students were also a suggestion as well as using social media and schools to educate parents on the importance of reading.

I felt that when going into a foreign land to learn about a culture, it was important to look at my studies from that culture's perspective, to be present to observe the sights, sounds, subtleties, to do background research, to be culturally sensitive, and to weigh out any dogmatic dilemmas of which my ethnographic research could encounter or potentially create. Additional suggestions for future studies that go along with this research could be the benefits and downfalls to improving literacy on Isla Mujeres and understanding the ways in which the economy, education, socioeconomic status, and residential status affect literacy in primary school students. Other possible studies could include learning how to integrate a better literacy education or curriculum into Isla Mujeres's public schools or how to create a program or campaign for fostering more reading programs and activities at home with families.

"Generally speaking, the majority of researchers have ignored the possibility that children who do not have access to many books but actively seek out opportunities for parents to read to them or who try to make sense of environmental print might learn as much or more than children who are surrounded with books and whose parents frequently attempt to involve them in reading events, but who are reluctant to participate. Thus, to fully understand what literacy abilities children learn in the home, it appears necessary to first determine whether the home environment can be conceptualized on a continuum of (a) rich to moderate availability of print, and (b) highly active to moderate participation by the child with the available print and the opportunities adults provide for such interactions." (Aulls \& Sollars, 2003, 164-178)

The key to improving literacy on Isla Mujeres, or perhaps anywhere, is first surveying parental attitudes on literacy and their perceptions about reading to their children. A lack of printed or digital reading material at home will affect a child's overall attitude towards the importance of reading. However, the parent's attitude and perceived importance of literacy at home will also affect student's literacy. Since this project has portrayed that there is great desire on this island for increased reading and literacy, one can easily take concepts developed here and move them forward into a future project.

\section{References}

Aulls, M.W., \& Valerie S. (2003). The differential influence of the home environment on the reading ability of children entering grade one. Reading Improvement, 40(4), 164-178. Retrieved from Education Source, EBSCOhost.

Gonzalez-Barrera, A., \& Hugo L. M. (2014). Spanish is the most spoken non-English

language in U.S. homes, even among non-Hispanics. Pew Research Center.

Jenkins, R. (2001). Oral reading fluency as an indicator of reading competence: a theoretical, empirical, and historical analysis. Scientific Studies of Reading, 5(3). 239-256.

LeCompte, M. D. and Schensul, J. J. (1999). Designing and conducting ethnographic research. AltaMira Press, 8586.

Leech, N. L., and Onwuegbuzie, A. J. (2008). Qualitative data analysis: A compendium of techniques and a framework for selection for school psychology research and beyond. School Psychology Quarterly, 23(4), 587-604.

Park, H. (2008). Home literacy environments and children's reading performance: A comparative study of 25 countries. Educational Research \& Evaluation, 14(6), 489-505. Retrieved from Professional Development Collection, EBSCOhost.

Segalowitz, N., \& Hulstijn, J. (2005). Automaticity in bilingualism and second language learning. Handbook of bilingualism: Psycholinguistic approaches, 371-388.

Shanker, J. L. \& Cockrum, W. A. (2014). Reading Inventory. Pearson Education Inc.

Symonds, Percival M., and Albert E. (1945). The case study as a research method. Review of Educational Research, 15(5), 352-59. Retrieved from http://www.jstor.org/stable/1168314.

Wolcott, H. F. (1994). Transforming qualitative data: Descriptions, analysis, and Interpretation., 13. Sage Publications, Inc. 